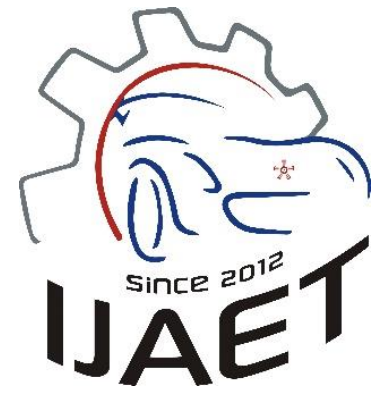

e-ISSN: 2146 - 9067

International Journal of Automotive

Engineering and Technologies

journal homepage: http://ijaet.academicpaper.org

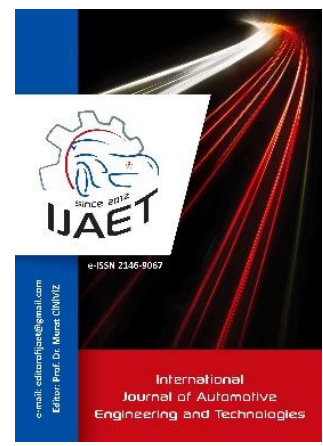

Original Research Article

\title{
Investigation of Diesel Engine Performance and Emissions by Multi-Dimensional Modeling
}

hosted by

JourkinalPark

\author{
Hasan Koten ${ }^{*}$ \\ *Department of Mechanical Engineering, Engineering Faculty, Istanbul Medeniyet University, Kadikoy, Istanbul, 34722, Turkey
}

\section{ARTICLE INFO \\ * Corresponding author hasan.koten@medeniyet.edu.tr hkoten@gmail.com \\ Received: January 18, 2018 Accepted: May 25, 2018 \\ Published by Editorial Board Members of IJAET \\ (C) This article is distributed by Turk Journal Park System under the CC 4.0 terms and conditions.}

\begin{abstract}
In automotive industry the new combustion processes focused on clean diesel combustion, decrease emissions such as particulate matter, NOx emission, unburned hydrocarbons ( $\mathrm{HC})$ and carbon monoxide $(\mathrm{CO})$ emissions. At this point, prediction of in-cylinder combustion behavior, effects of turbulence levels, flow structures and emission modeling have an importance to design efficient engines. In this study, diesel engine combustion was modelled by a development combustion model Extended Coherent Flame Models 3 Zones (ECFM-3Z). During this modeling, a calculation was made about an engine configuration with compression, spray injection, combustion and emission of the diesel engine with direct injection. Effects of in-cylinder flow structures, fuel injection and design parameters were investigated for the engine performance and emission results. The results agree qualitatively with experimental and also zero dimensional computational studies.
\end{abstract}

Keywords: Diesel Engine; CFD; Heat Release; Combustion; Emission; Performance.

\section{Introduction}

Internal combustion engine CFD calculations generally have complex and nonsymmetrical geometry and especially combustion modeling in moving geometry makes the study complicated. In moving parts, the valves are aligned with the cylinder axis or they can be "canted", i.e. they are at an angle to the cylinder axis and normal to the surfaces of the cylinder [1]. In literature, CFD validation, a $20^{\circ}$ bend angle having varying cross-sectional area intake ports is considered in results. The obtained results are compared with the experimental results [2-3]. In combustion modeling, the significant feature of the diesel engine is the use of liquid hydrocarbon fuel. The liquid fuel injected through the injector breaks up, atomizes and evaporates in a high temperature chamber and burns as being mixed with air. During the break-up, fuel spray, atomization and vaporization mainly depend on the air entrainment with a higher velocity and the higher temperature inside the engine cylinder [4].

The statistical Design of Experiments (DOE) technique as Response Surface Method (RSM) and optimization studies, by combining 
Computational Fluid Dynamics (CFD) modeling, and are used to develop the combustion chambers. This method is intensely helpful to get knowledge on the effect relationships, additively to the definition of the optimum set of values for the input parameters [5].

Choi et al. investigated the effect of the combustion chamber geometry and a double row nozzle with 12 holes on the emissions [6]. Atmanli et al. worked on a Response Surface Method to find the optimum diesel-n-butanolcotton oil ternary blend ratios also to reduce emissions [7]. These studies have been widely applied also to the analysis and optimization of advanced combustion strategies. Genzale et al. tested how the emissions are affected by the combustion chamber geometry operating with the low temperature combustion (LTC) concept [8]. Benajes et al. studied the potential of the piston geometry to improve the results provided by the Reactivity Controlled Compression Ignition (RCCI) concept in terms of thermal efficiency and exhaust emissions [9]. In addition, the experimental optimization of parameters related to the engine equipment, such as the piston bowl or the injector parameters is costly in terms of time and resources because it involves piston or injector manufacturing and assembling. As known, CFD methods are gaining reliability in predicting exhaust emissions and engine performance by using properly calibrated and validated models. Also, CFD technique is an alternative compared to the experimental technique especially for the optimization of the engine hardware due to its lower requirements in terms of equipment and time. Moreover, CFD technique is suitable to define the optimum engine settings configuration and to identify qualitatively and quantitatively the most relevant effects of the parameters to be optimized. A lot of studies have been carried out in literature using CFD and experimental methods [10-11].

In internal combustion engine (ICE) design, CFD tools are very useful and powerful to understand the multi-physics phenomenon. In this study, it is aimed to find out the combustion characteristics of a single-cylinder, 1-lt CI engine including detailed fuel injection and atomization process in order to investigate the engine performance and emissions. Also complete intake and compression stroke, fuel injection at the end of the compression stroke, combustion and emission simulated in 3D. Both naturally aspirated and turbo-charged modes of operations were studied.

Real engine geometry of one-liter singlecylinder diesel engine was modelled including exhaust and inlet manifolds. In multidimensional modeling simulations were extended for both intake and exhaust ports to get proper boundary conditions at the valve lifts. Fine grids were tested with 1,500,000. Fine grid results are presented in the paper. Typical execution time for $408{ }^{\circ} \mathrm{CA}$ with fine meshes takes about 5 days on a workstation with 16 processors running in parallel processing.

As seen in literature, the most general methodology to solve fluid flow is based on modeling of the Navier-Stokes equations. This methodology includes that the continuity equation, Navier-Stokes equations of momentum and the energy equation are discretized to solve a specific fluid problem limited in space and divided in a large number of computational cells [12]. In time discretization, the entire sub-system was discredited into smaller volumes, where a flow split was represented by a single volume and pipes are divided into several volumes [13]. In methodology, if we put $\mathrm{Y}(\mathrm{t})$ in the current system state and $\mathrm{Y}(\mathrm{t}+\Delta \mathrm{t})$ in the state at the later time ( $\Delta \mathrm{t}$ is a small time step), then the explicit method is: $\mathrm{Y}(\mathrm{t}+\Delta \mathrm{t})=\mathrm{F}(\mathrm{Y}(\mathrm{t}))$ The time step during this integration is limited by the Courant condition [14], which restricts the time step to be less than 0.8 of the time required for the pressure and flow to propagate across any discredited volume:

$$
\frac{\Delta t}{\Delta x}(u+c) \leq 0.8
$$

$\Delta \mathrm{x}$ where $\Delta \mathrm{t}$ is the time step, $\Delta \mathrm{x}$ the discretized length, $\mathrm{u}$ the fluid velocity and $\mathrm{c}$ the speed of sound. Using small time steps, the flow is reached by explicit time integration of the equations for continuity, momentum and energy [15]. Spray injection and mixture formation modeling using CFD in IC engines is a multicomponent multiphase problem that contains liquid fuel and the various species that participate in mixture formation. Commonly, 
the gas phase is treated in an Eulerian approach, which means that the property of a fluid $\varphi$ is computed in each cell, i.e. $\varphi(\mathrm{x}, \mathrm{y}, \mathrm{z}, \mathrm{t})$. The liquid phase is treated in a Lagrangian approach, which means that an individual particle is traced and the property of this particle is calculated as it moves through the domain as a $\varphi(t)$. The interaction between the phases is accounted for by source terms in the Eulerian gas phase [15].

The equations of motion for the fluid phase can be solved turbulent flow for in-cylinder motion. The equation for conservation of species mass fraction $Y \alpha$, momentum equation and energy equation are given in the following equations [12].

$$
\frac{\partial}{\partial t}\left(\rho Y_{\alpha}\right)+\frac{\partial}{\partial x_{i}}\left(\rho Y_{\alpha} U_{i}\right)=\frac{\partial}{\partial x_{j}}\left(D \frac{Y_{\alpha}}{\partial x_{j}}\right)+\rho \dot{r}_{\alpha}+\dot{\rho}_{s}
$$

\section{Mathematical Modeling}

$$
\begin{aligned}
& \frac{\partial}{\partial t}\left(\rho U_{i}\right)+\frac{\partial}{\partial x_{j}}\left(\rho U_{i} U_{j}\right)=-\frac{\partial p}{\partial x_{i}}+\frac{\partial}{\partial x_{j}}\left\{\mu\left[\frac{\partial U_{i}}{\partial x_{j}}+\frac{\partial U_{j}}{\partial x_{i}}-\frac{2}{3} \frac{\partial U_{k}}{\partial x_{k}} \delta_{i j}\right]\right\} \\
& \frac{\partial}{\partial \mathrm{t}}(\rho E)+\frac{\partial}{\partial x_{j}}\left(\rho E U_{j}\right)=\frac{\partial p}{\partial \mathrm{t}}+\frac{\partial}{\partial x_{j}}\left(\sigma_{i j} U_{j}\right)+\frac{\partial}{\partial x_{j}}\left(\lambda \frac{\partial T}{\partial x_{j}}\right)+\rho \dot{q}_{g}+\dot{Q}_{s}
\end{aligned}
$$

Turbulent flow is present in most realistic flow situations. When turbulent flow is considered, it is advisable to express the instantaneous velocity by a mean and a fluctuating part. For instance, the velocity can then be expressed as follows:

$$
U_{i}=\left\langle U_{i}\right\rangle+u_{i}
$$

The mean component $\mathrm{U}_{\mathrm{i}}$ can be calculated in three different ways: time average $\left(\bar{U}_{i}\right)$, density average $\left(\bar{U}_{i}\right)$ and ensemble average $\left(\hat{U}_{i}\right)$ according to the following equations.

$$
\begin{aligned}
& \bar{U}_{i}=\lim _{\tau \rightarrow \infty} \frac{1}{\tau} \int_{0}^{\tau} U_{i}\left(x_{i}, t\right) d t \\
& \rho \bar{U}_{i}=\lim _{\tau \rightarrow \infty} \frac{1}{\tau} \int_{0}^{\tau} \rho U_{i}\left(x_{i}, t\right) d t \\
& \hat{U}_{i}=\lim _{n_{e} \rightarrow \infty} \frac{1}{n_{e}} \sum_{i=1}^{n_{e}} U_{i}\left(x_{i}, t\right)
\end{aligned}
$$

Two equation models are the most wide-spread models used in averaged Navies-Stokes simulation. By avoiding the problem inherent to the former models, namely requiring the specification of a flow-dependent length scale, they provide both a length and a time-scale by solving an additional equation. The simplest one is the standard $\mathrm{k}-\varepsilon$ model, which is widely used in turbulence simulations because of its general applicability, robustness and simplicity. The two transport equations for the kinetic energy and dissipation rate are solved to form a characteristic scale for both turbulent velocity and length. The RNG k- $\varepsilon$ turbulence model is derived from the Navier-Stokes equations using a mathematical technique called "renormalization group" (RNG) methods. The analytical derivation results in a model with different constants than those in the standard k$\varepsilon$ model. This model is based on the Wilcox k- $\omega$ model [16]. It incorporates modifications for low-Reynolds number effects, compressibility and shear flow spreading. The Wilcox model predicts free shear flow spreading rates that are in close agreement with measurements for far wakes, mixing layers and different types of jets [17]. In spray modelling, there are numerous additional models for spray injection, spray breakup, droplet collision, evaporation, wall impingement, ignition, combustion etc. CFD code used contains built-in capabilities for modeling the behavior of special-purpose atomizers (nozzles) used in fuel-injected internal combustion engines. The injection process being modelled includes the flow in the nozzle hole (most importantly its exit velocity) and atomization. The latter gives rise to a fuel droplet spray represented by a set of computational parcels, each containing a number of droplets with the same properties (velocity, size, temperature, density, etc.). These properties are calculated on the basis of various atomization models whose characteristics and assumptions are given below. The histories of 
the computational parcels are obtained from the Lagrangian conservation equations of mass, momentum, and energy in the normal way [18, 19]. In atomization model, Huh's model was used as an atomization model in the simulations. This model is based on the premise that the two most important phenomenas in spray atomization are the gas inertia and the internal turbulence stresses generated in the nozzle [20]. The fuel particles may become unstable due to the interfacial forces acting on their surfaces during the relative motion according to the continuous phase. This problem was solved by using the break-up model of Reitz and Diwakar [21]. The collision model of O'Rourke was used for inter-droplet collisions in the computations. And also it was improved with a speed-up algorithm of Schmidt and Rutland [22, 23]. Moreover, this model includes a coalescence timescale highlighted by Aamir and Watkins [24].

Bai's Spray impingement model was used in the simulations as a wall-interaction model for discrete phase. This model was formulated within the framework of the Lagrangian model, which is based on literature findings and mass, momentum and energy conservation constraints [25].

\section{Combustion and Emission Modeling}

Wiebe function for $1 \mathrm{D}$ approximation and Extended Coherent Flame Model (ECFM) for 3D CFD solution are used to carry out Combustion modelling. The Wiebe function can be expressed follows:

$$
x_{b}=1-\exp \left(-a\left(\frac{\theta-\theta_{0}}{\Delta \theta}\right)^{m+1}\right)
$$

Where $\mathrm{x}_{\mathrm{b}}$ is the mass fraction burned, $\theta$ is the crank angle, $\theta_{0}$, which fixes the timing is the crank angle at the start of combustion, a and $\Delta \theta$ are adjustable constants that determine the combustion duration and $\mathrm{m}$ is an adjustable parameter that fixes the shape of the combustion progress curve.

The Extended Coherent Flame Model (ECFM) [26] and the 3-Zone ECFM (ECFM-3Z) broadly belong to the Coherent Flame Model (CFM) family, but are extended to non-homogeneous turbulent premixed and unpremixed (diffusion) combustion. In the ECFM3Z combustion model, the state of the gases mixture is defined in the 2D space. It is simultaneously described in terms of mixing and progress of reaction as schematically represented in Fig. 1 [27-28].

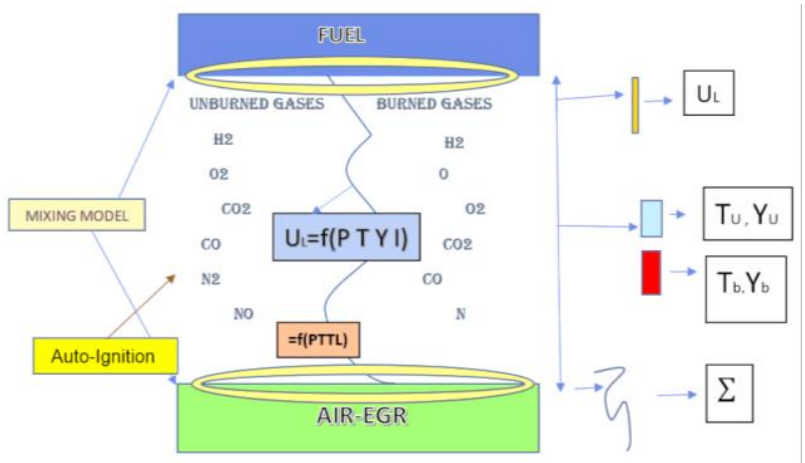

Figure 1. Schematic of the ECFM-3Z model computational cell.

The differential equations are formulated in a density-weighted ensemble-averaged frame to facilitate the use of mathematical models of the turbulent transport and combustion processes. Generally, ECFM-3Z can be used for all types of combustion regime whereas ECFM, being a subset of ECFM-3Z, is mostly suitable for nonhomogeneous turbulent premixed combustion with spark ignition. As part of these models, two options are provided for modeling spark ignition:

A spark ignition model employing a correlation to account for the delay between spark and flame kernel appearance. A more complex model (AKTIM) where the physics of the spark are modeled in more detail. On the subject of auto ignition, two options are also provided, a simple model and a double-delay model for more accurate predictions, especially with engine simulations.

For emission simulation, the 3-step Zeldovich model is available for NOx and three options are provided for soot [28]. The Mauss model based on a pre-computed soot source-term library and the PSDF model of moments, where the soot particle size distribution are transported. The moment source terms are calculated using the soot flamelet library.

The soot formation reaction model uses an Arrhenius rate. The soot oxidation assumes two different reactive sites and the resulting oxidation rate is a function of soot properties $\left(\rho_{\mathrm{s}}\right.$ : density, $D_{s}$ : average diameter) and other kinetic parameters. The predicted soot emission is a result of the competition between formation and oxidation reactions. 
Net soot mass $=$ Soot mass formed - Soot mass oxidized

$$
=A_{s f} M P^{0.5} \exp \left(-\frac{E}{R T}\right)-\frac{6 M W}{\rho_{S} D_{S}} M_{S} R_{\text {total }}
$$

The NOx model uses the extended Zeldovich NO mechanism where, basically, there are no adjustable model constants. However, a scaling factor is provided for model calibration that accounts for differences in the computed NOx and measured NOx level based on different experimental techniques.

\section{Computational Grid}

The engine that is modelled is a single-cylinder 1lt light-duty diesel real engine. The geometrical specifications of the engine, as well as the engine's original valve timings are summarized before chapter. The computational grid and mesh dependency are shown in Fig. 2. It consists of about 800,000 cells at TDC. As it can be seen, the grid resolution is not adequate to capture the details of the boundary layer and the top-land crevice of the piston. This prevents the prediction of the low temperature regions in the cylinder, which can account for $5-10 \%$ of the

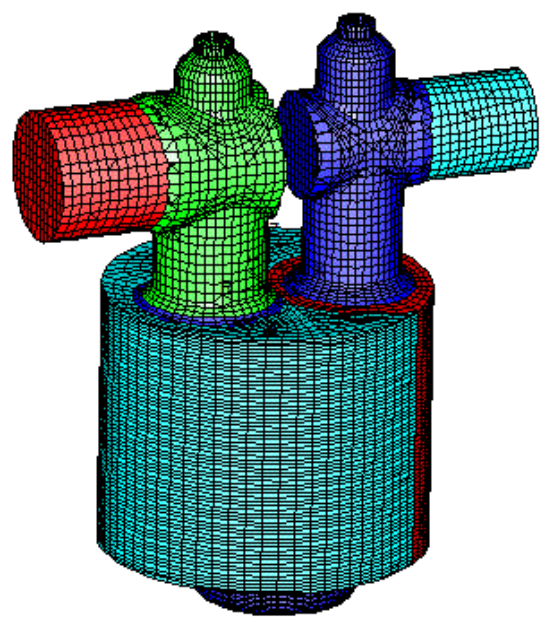

Figure 2. Engine mesh structure view and mesh dependency.

\section{Boundary Conditions}

In this study, single cylinder diesel engine combustion phenomenon was analyzed within a multi-dimensional framework under operating conditions given in Table1 and Table2. All the walls were treated with the turbulent law-of-thewall. The heat fluxes to the walls are calculated assuming constant wall temperatures.

The prescribed boundary condition at the inlet of the intake port is that of "pressure inflow",

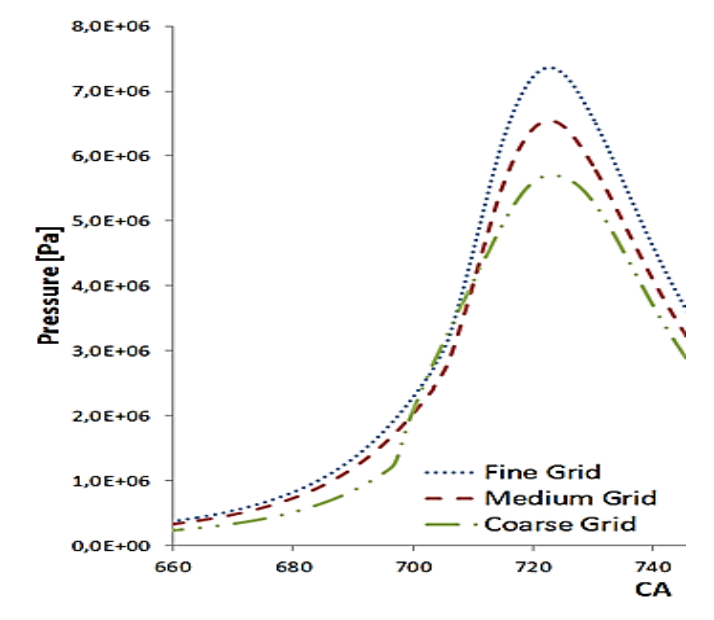

total mass in the cylinder and are the main contributors to reduced combustion efficiency and increased unburned hydrocarbon emissions. This problem could be overcome by increasing the grid size; however this would increase dramatically the computational time. A finer grid could include the top-land crevice. In addition, a crevice model could be introduced in commercial CFD software, in order to simulate flow in the crevices and blow-by. Nevertheless, even though the low temperature regions are not captured well commercial CFD software, can still provide reasonable predictions for the bulk temperature in the cylinder and the overall temperature and composition distributions.

All the calculations were performed by means of the CFD code. The moving mesh (i.e. piston and intake valves regions) is provided be CFD code's tool designed to facilitate transient analyses of internal combustion engines. CFD solver pre-processor creates the fixed mesh (intake and exhaust ports). The computational grid is made up of cells of mainly hexahedral shape, whose number ranges from approximately 800.000 at TDC up to over 1.500.000 at BDC for fine mesh.

while that at the outlet of the exhaust port is "pressure outflow".

\begin{tabular}{lr}
\multicolumn{2}{c}{ Table 1. Engine properties. } \\
\hline Bore / Stroke & 0.96 \\
Connecting Rod Length (mm) & 131 \\
Piston Pin Offset (mm) & 0.00 \\
Displacement/Cylinder (cc) & 365.25 \\
Total Displacement (liter) & 1 \\
Number of Cylinders & 1 \\
Compression Ratio & 17.8 \\
\hline
\end{tabular}


Table 2. Operating conditions.

\begin{tabular}{ll}
\hline Engine speed & $2000 \mathrm{rpm}$ \\
Mass of fuel injection & $7 \mathrm{~kg} / \mathrm{h}$ \\
Intake pressure & $1.3 \mathrm{bar}$ \\
Intake temperature & $312 \mathrm{~K}$ \\
\hline
\end{tabular}

\section{Engine Simulation}

In cold flow study, moving mesh feature was used to analyses the flow structure inside the combustion chamber. Cold flow simulation in $3 \mathrm{D}$ was investigated as intake and compression strokes. Both intake and compression strokes were simulated including full geometry, intake port, exhaust port, intake valve, exhaust valve and combustion chamber in transient condition.

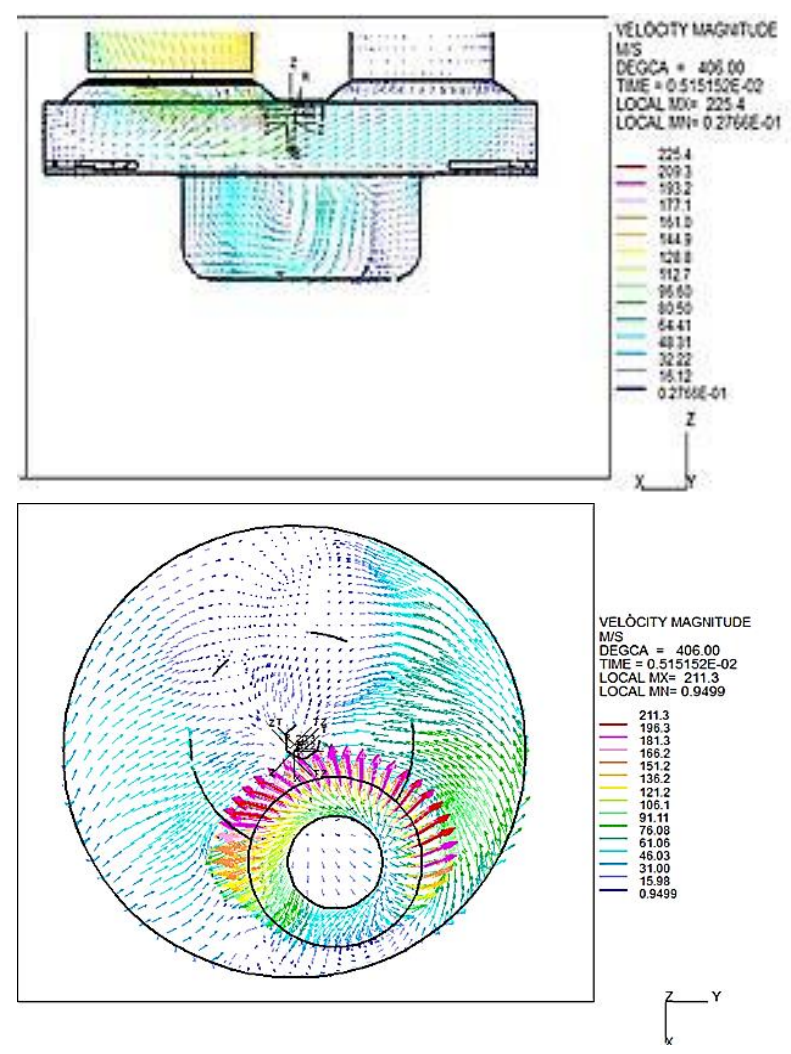

Figure 3. Velocity vectors in different views.

Different flow structures can be easily distinguished inside the cylinder. The vector field shows less large structures and larger vortices can be seen Fig. 3. As shown in Fig. 3, in a larger distance from the cylinder head, these vortices start to become small structure. During the intake stroke, air flow field under the valves has disordered structure. Smaller vortices and smaller vortex flow structures can be seen inside the combustion chamber in Fig.3. Swirl flow structures can be also seen and the magnitude of the velocity vectors decreased compared to the previous vector fields. Moreover, at the bottom of the cylinder, higher velocity vectors can be seen in a clockwise swirl structure.

The induction stroke of the previous section was followed by the compression stroke. In case of compression stroke, not only the velocity fields but also the kinetic energy fields were evaluated. The kinetic energy is directly depended on turbulence phenomenon and air fuel mixture will be occurred just after the end of the compression stroke. Through the compression stroke vector fields have more homogeneous structure when compared to the intake stroke. As shown in figures there are some vortices which have less intensity. At the beginning of the compression stroke large clockwise swirl structures exist. When piston goes from BDC to TDC, magnitude of the swirl structure decreases during the compression stroke. The velocity magnitude during the compression stroke decreases due to friction causes less intensity on the flow structure. Velocity vectors were evaluated in all direction. The maximum air flow velocity was obtained around the maximum valve lift. After maximum valve lift, velocity vectors gradually decrease during the intake stroke and compression stroke. Turbulence and air velocities generated purely during the compression stroke are much smaller than those generated during the intake stroke and can therefore be neglected [29]. During the compression stroke velocity vectors start to decrease due to the friction as shown in figures. During the compression stroke, turbulence dissipates due to the decrease of kinematic viscosity and increase of temperature and pressure. At the beginning of the compression stroke, higher velocity levels are necessary to have high turbulence intensity for a good air fuel mixture at the end of the compression stroke.

Contours of the z-velocity were depicted in Fig. 4 to analyses parallel flow to the cylinder axis. Air flow was still influenced by the flow features of the induction stroke at $586^{\circ} \mathrm{CA}$. Air flow is largely driven by the piston movement half of the compression stroke because of there is no extra energy entrance by the compression and z-velocity contours were flattened. Turbulence level is very effective on the combustion process turbulence and thus inextricably connected to the turbulent kinetic energy. The kinetic energy is directly related to the velocity magnitudes. It is therefore not 
surprising that the kinetic energy, as well as the velocity, decreases with increase of crank angle. This decrease of kinetic energy starts rapidly. At TDC in Fig. 4 (a) when looked at to velocity magnitudes about half of the maximum kinetic energy is increased compared to the BDC. Velocity magnitude inside the cylinder was shown in Fig. 4 (b). This also will provide high kinetic energy levels.

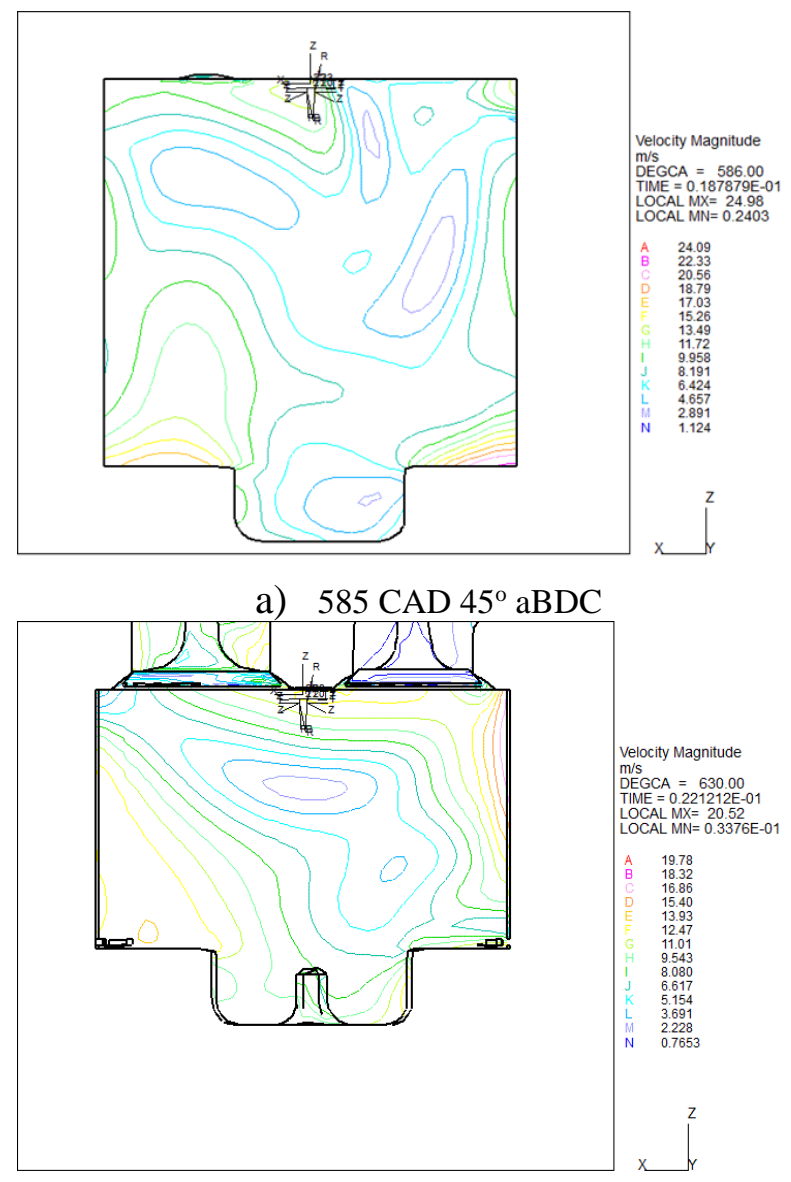

b) $630 \mathrm{CAD} 90^{\circ} \mathrm{aBDC}$

Figure 4. Contours of velocity at different crank angles during the compression stroke.

Several calculations for the flow in the engine cylinders have been previously carried out and established on the literature. Zur Loye et al. (1989) and Kono et al. (1999) performed calculations of the compression stroke. In particular, Kono et al. presented the analysis of the swirl intensity effects on spray formation and obtained reasonable agreement with experimental data. However, since the intake process was not included in Kono's calculation, the initial swirl was entered as a parameter. In this study, intake and exhaust strokes were added in the calculation and swirl intensity effects on spray formation in simulation at different crank angles [30-48]. In this study,
AVL FIRE CFD code was used as software. In meshing geometry, hexahedral cells which are proper for moving mesh were used in edge size of $0.8 \mathrm{~mm}$. RNG k-e model as turbulence, ReitzDiwakar model was used to model spray, Wiebe function for 1D combustion and ECFM-3Z were used for 3D combustion, Mauss model for soot, 3-step Zeldovich mechanism for NOx emission were used. In injector geometry, four holes were defined with $171 \mu \mathrm{m}$ diameter. Nozzle size was selected from software library and injection pressures were calculated by mass flow rate.

\subsection{Spray Modeling}

Diesel fuel injector was defined at the center of cylinder. As seen in Fig. 5 the fuel is injected directly to the combustion chamber. If the fuel spray velocity is high enough, fuel air mixture generates an additional flow vortex in the fuel spray direction and therefore some fresh air is driven to the piston bowl dome, replacing the fuel/air mixture, allowing the second and more injection to take place in a 'fresh' air area and hence leading to improved bulk air utilization [17].

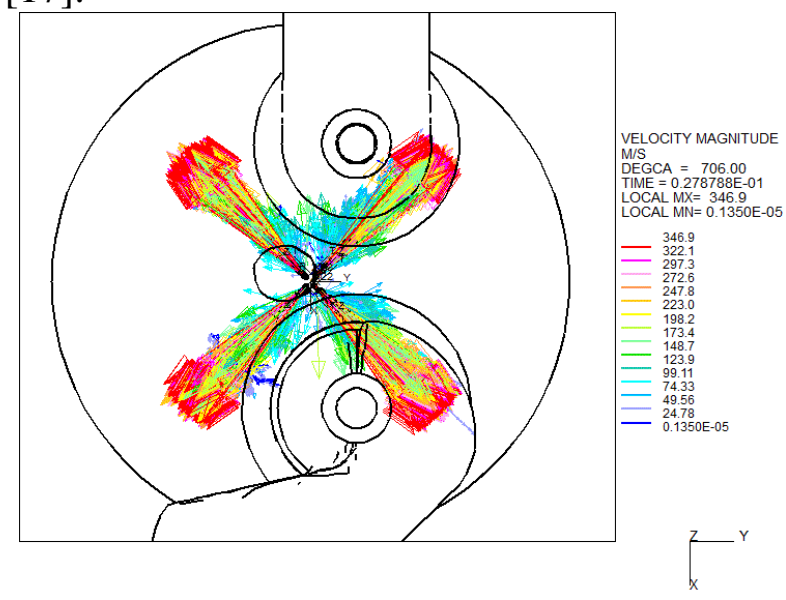

Figure 5. Spray simulation for diesel fuel.

In addition, the combustion process in true spray injection process allows better control of maximum heat release leading to less combustion noise and NOx emissions. Also, early injection timing occurs at the pre-heat release by low temperature oxygen reactions before combustion. Several injection strategies were introduced as a concept of ignitionenhancing to solve the problem in wall wetting [39]. According to literature review, injection strategies are very effective on exact combustion and exhaust emission. In 1D and 3D spray simulation, real engine injector data were 
used. Injection strategy was modeled by injecting of fuel near TDC; diesel fuel was injected at $12^{\circ}$ bTDC. 1D, 3D and real engine experimental results were obtained and good agreement each other. In CFD calculation, injector which has four holes was defined using cylindrical coordinate system. Start of injection, spray duration defined using $\mathrm{CAD}$, cone angle and hole diameter were defined in millimeter.

Diesel fuel injector nozzle was defined with spray cone angle to get exact combustion inside the combustion chamber. As can be seen from Fig. 6, spray and combustion simulation were performed by choosing proper parameters for fuel operations.

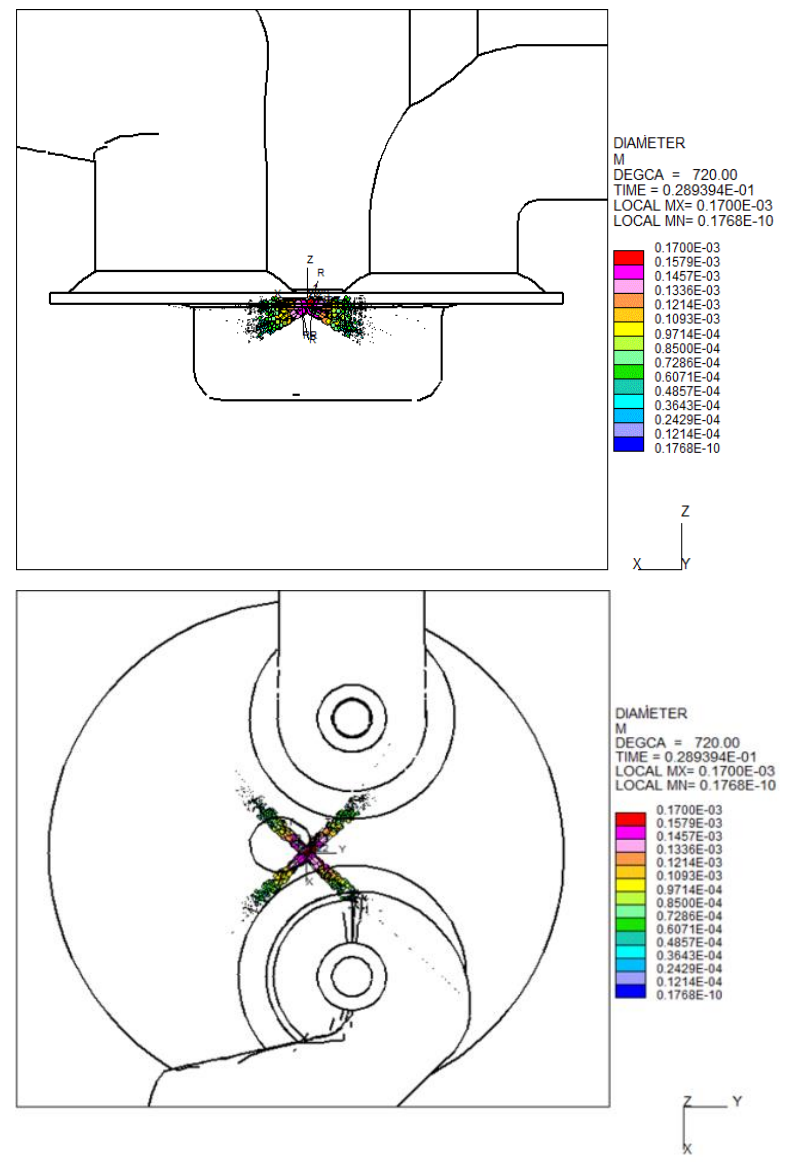

Figure 6. Contours of droplet diameters for diesel fuel.

Fig. 6 shows the result of spray simulation in real engine geometry with four injection points on the injector. Fuel particles follow mainly the bowl shape and recirculation motion generated inside the bowl as can be seen in these figures. On the other hand, Fig. 6 shows that the horizontal cross-section spray simulation was affected from the flow structure. In addition, fuel consumption of diesel fuel was decreased especially in specified engine conditions.

\subsection{Combustion and Emission Results}

1D engine code was used to simulate engine performance and exhaust emissions such as $\mathrm{CO}$ and NOx gases. The combustion pressure and in-cylinder temperature were evaluated under engine geometry conditions in order to verify $3 \mathrm{D}$ and experimental results. Wiebe function for 1D approximation and Extended Coherent Flame Model (ECFM) for 3D CFD solution were used to carry out combustion modeling. 3D engine code was used to find out flow structure in-cylinder and behavior of the mixture combustion. Results reported in this section the engine operating conditions of $2000 \mathrm{rpm}$ and diesel fuel injection with $7 \mathrm{~kg} / \mathrm{hr}$. The detailed operating conditions are listed in Table 2. The $3 \mathrm{D}$ results at the level of TDC were shown in Fig. 7 with a section that passes through the cylinder center.

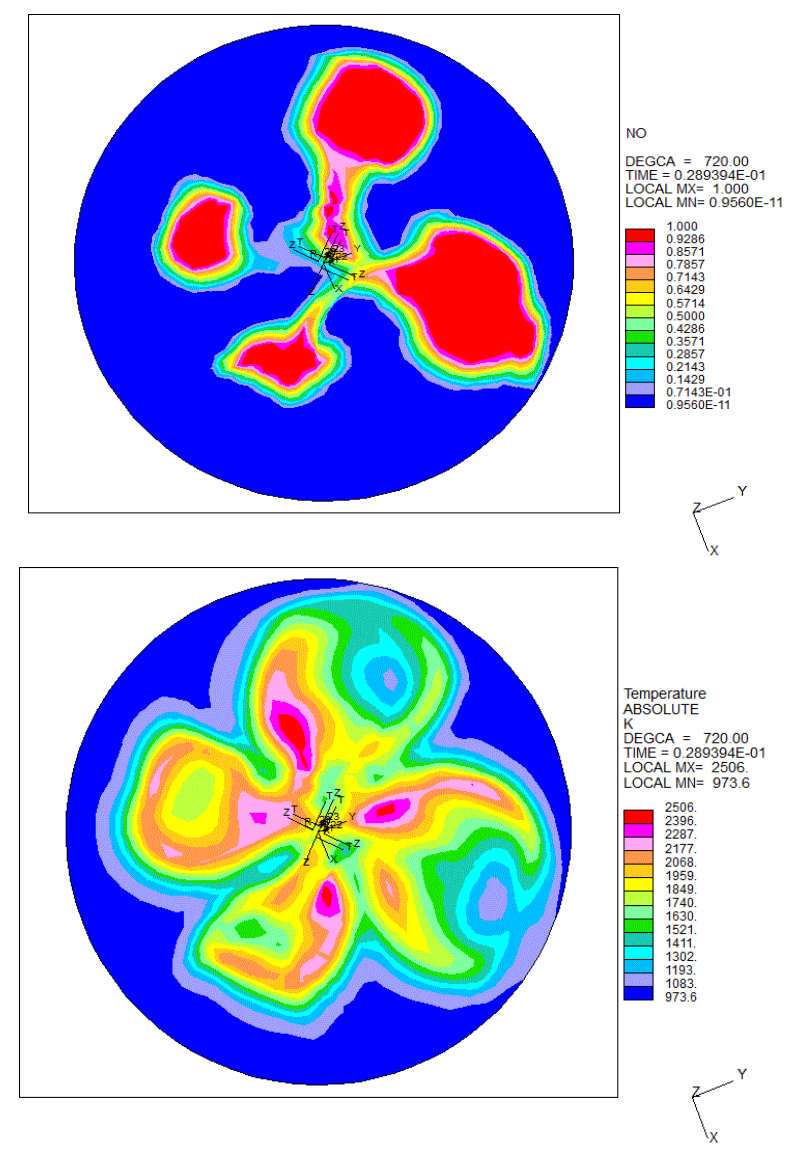

Figure 7. 3D NOx emission and temperature contours at TDC.

Because of the shifting of combustion event to earlier side, this causes the increase of negative operating conditions for a conventional diesel engine. These trends are regarded as typical problems of injection strategies and injection rates that lower the thermal efficiency and 
increase the incomplete combustion products such as the $\mathrm{HC}$ and $\mathrm{CO}$ emissions [40, 41].

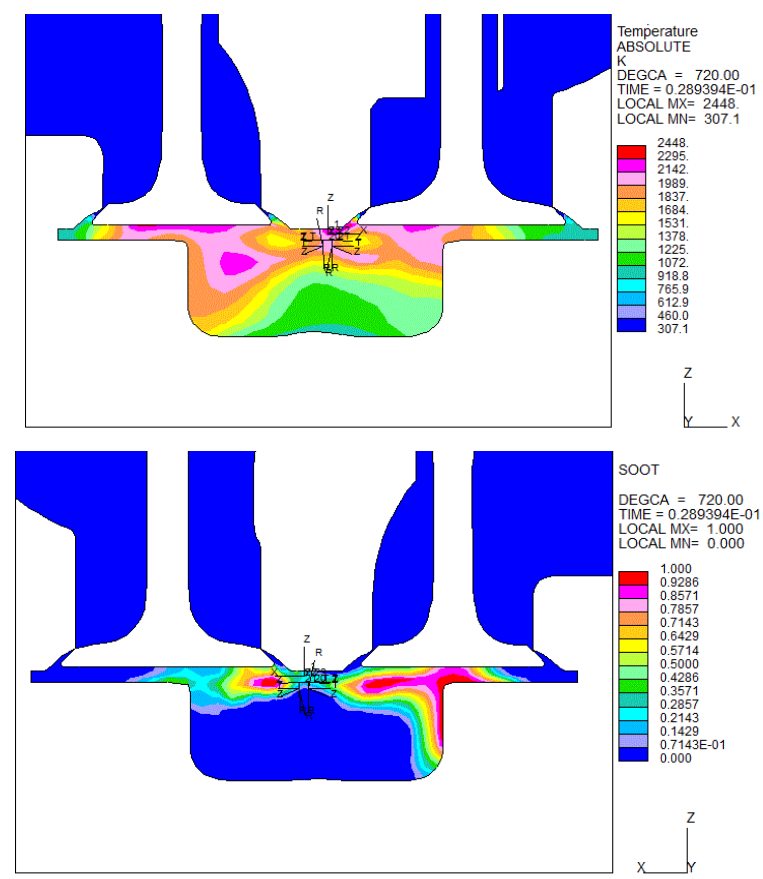

Figure 8. 3D NOx and Soot emission contours at TDC in $+\mathrm{Y}$ direction.

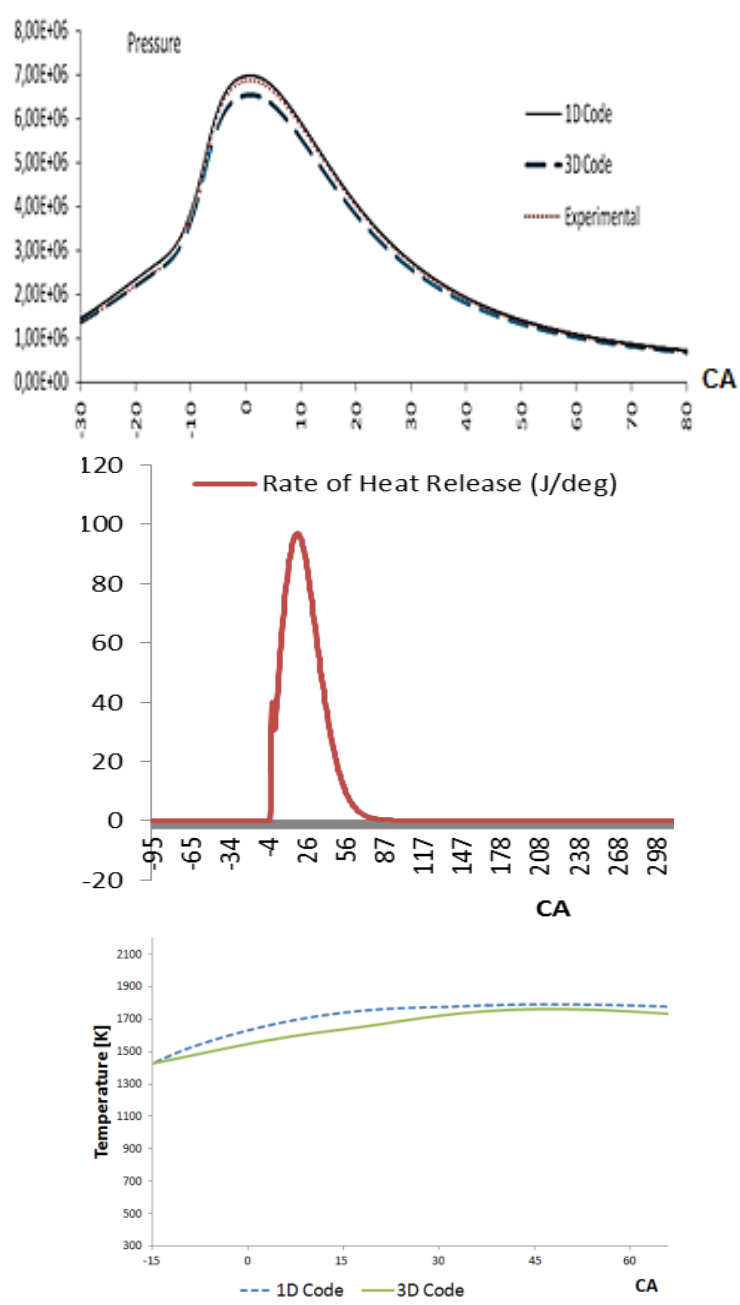

Figure 9. 1D, 3D and experimental engine performance
1D engine code was employed to validate 3D results as shown in Figure 9. ECFM and the 3Zone ECFM (ECFM-3Z) broadly belong to the Coherent Flame Model (CFM) family, but are extended to non-homogeneous turbulent premixed and unpremixed (diffusion) combustion. In the ECFM-3Z combustion model, the state of the gases mixture was defined in the 3D space. In-cylinder 1D pressure value is slightly bigger than $3 \mathrm{D}$ engine simulation and experimental results as shown in Figure 9. 1D, 3D pressure value reached maximum value near $4^{\circ} \mathrm{CA}$ aTDC however, experimental analysis reached a few degree crank angle later than engine codes, (near $6^{\circ} \mathrm{CA}$ aTDC, Figure 9). At the same time, 3D temperature results reached maximum value near $3^{\circ} \mathrm{CA}$ aTDC and 1D analysis yields a maximum about $20^{\circ} \mathrm{CA}$ aTDC (Figure 9). It is shown that a few difference between 1D, 3D CFD and experimental results possibly due to the injection parameters used in CFD calculation (i.e. maximum droplet and parcel number). In figure 10, NOx and CO emissions were compared for 1D and 3D analyses.

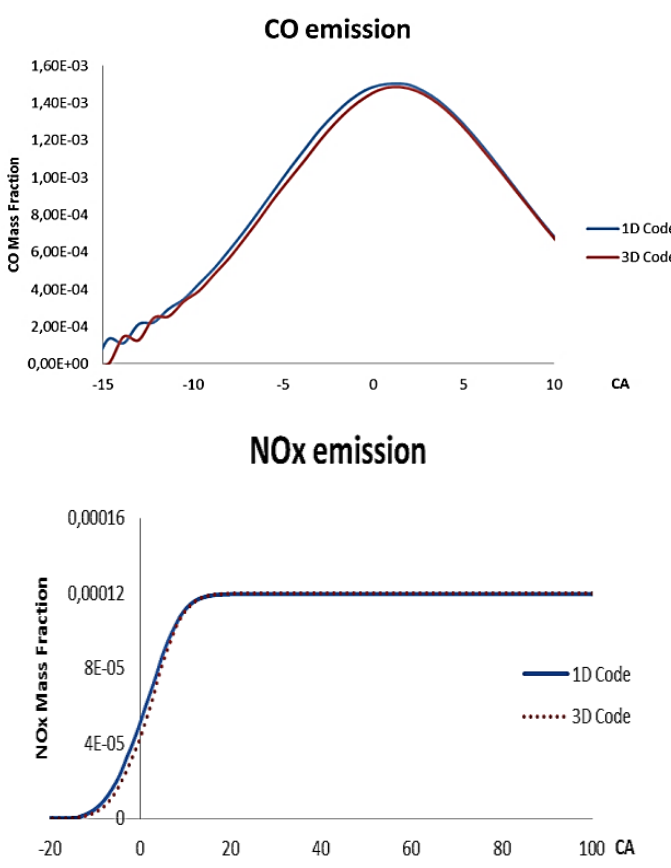

Figure 1. In-cylinder CO and NOx mass fraction results

\section{Conclusions}

In this study, development combustion model ECFM-3Z has been employed successfully to get more information about the in-cylinder combustion and emission events. Effect of incylinder design parameters on cold flow 
structure and performance in a diesel engine were investigated and reported. Pressure and temperature distributions were also in the expected ranges according to validation results. In cold flow part, turbulence models were tested includes k- $\varepsilon /$ Standard, k- $\omega, \mathrm{k}-\varepsilon / \mathrm{RNG}$, Chen's k$\varepsilon$ and $\mathrm{k}-\varepsilon /$ Speziale to find the optimum model and selected proper models. 1D and 3D analyses results illustrated that turbulence is driven by combustion effect. 1D and 3D results have little difference due to dimensional differences. Swirl and tumble which are a result of intake port also squish flow motion inside the combustion chamber were also affected 3D results. Also, fuel injection at high inlet pressure was another main parameter on turbulence level and 3D results. During intake stroke results, as the intake valve opens an impingement to the cylinder wall occurs from above the valve which creates levels of turbulence kinetic energy as high as $130 \mathrm{~m}^{2} / \mathrm{s}^{2}$ at $80{ }^{\circ} \mathrm{CA}$ aTDC. Also, different effects of injection parameters on the emission of diesel engine were presented.

\section{Acknowledgement}

This work has been supported by the Scientific Research Programme of Istanbul Medeniyet University with grant no: F-GAP-2017-944. The author would like to thank the institution for supporting this research project.

\section{Abbreviations}

\begin{tabular}{|c|c|}
\hline $\mathrm{aBDC}$ & : after bottom dead center \\
\hline aTDC & : after top dead center \\
\hline BDC & : Bottom Dead Center \\
\hline BMEP & : Brake Mean Effective Pressure \\
\hline $\begin{array}{l}\text { Bsfc } \\
(\mathrm{g} / \mathrm{kWh})\end{array}$ & : Brake specific fuel consumption \\
\hline $\mathrm{CO}$ & : Carbon monoxide \\
\hline $\mathrm{CR}$ & : Compression Ratio \\
\hline $\begin{array}{l}\text { HCCI } \\
\text { Ignition }\end{array}$ & : Homogeneous Charge Compression \\
\hline $\mathrm{NOx}$ & : oxides of nitrogen \\
\hline PCCI & : Premixed Charge \\
\hline Ignition & \\
\hline PM & : Particulate Matter \\
\hline PPCI & Premixed-Charge \\
\hline Compress & ition \\
\hline ROHR & : Rate of Heat Release \\
\hline SIMPLE & : Semi-Implicit Method for Pressure- \\
\hline Linked Ec & \\
\hline $\mathrm{SOC}$ & : Start of Combustion \\
\hline SOI & : Start of Injection \\
\hline TDC & : Top Dead Center \\
\hline UHC & : total Unburned Hydro Carbon \\
\hline
\end{tabular}

\section{References}

1. Vijayashree, Ganesan V. 2018, Application of CFD for Analysis and Design of IC Engines. In: Srivastava D., Agarwal A., Datta A., Maurya R. (eds) Advances in Internal Combustion Engine Research. Energy, Environment, and Sustainability.

2. Amin M, Saray RK, Shafee S, Ghafouri J. 2013, Numerical study of combustion and emission characteristics of dual-fuel engines using 3D-CFD models coupled with chemical kinetics. Fuel 106:98-105.

3. Payri F, Benajes J, Margot X, Gil A 2003 CFD modeling of the in-cylinder flow in directinjection diesel engines. Comput Fluids 33:9951021.

4. Cyril C, 2002 Combustion process in diesel engine. Ph.D. thesis, University of Brighton.

5. Jesus Benajes, et. al., 2016, Optimization of the combustion system of a medium duty direct injection diesel engine by combining CFD modeling with experimental validation, In Energy Conversion and Management, Volume 110, Pages 212-229, ISSN 0196-8904.

6. Choi S, Shin S, Lee J, Min K, Choi H. 2015, The effects of the combustion chamber geometry and a double-row nozzle on the diesel engine emissions. Proc Inst Mech Eng, Part D: J Automobile Eng; 229(5):590-8.

7. Atmanli A, Yüksel B, Ileri E, Karaoglan AD. 2015, Response surface methodology based optimization of diesel-n-butanol-cotton oil ternary blend ratios to improve engine performance and exhaust emission characteristics. Energy Convers Manage; 90:383-94.

8. Genzale, CL, Reitz RD, Musculus, MPB. 2008, Effects of piston bowl geometry on mixture development and late-injection lowtemperature combustion in a heavy-duty diesel engine. SAE technical paper.

9. Benajes J, Pastor JV, García A, Monsalve-Serrano J. 2015, an experimental investigation on the influence of piston bowl geometry on RCCI performance and emissions in a heavy-duty engine. Energy Convers Manage; 103:1019-30.

10. Park SW. 2010, Optimization of combustion chamber geometry for 
stoichiometric diesel combustion using a micro genetic algorithm. Fuel Process Technol; 91(11):1742-52.

11. Yu Li, Hailin Li, Hongsheng Guo, Yongzhi Li, Mingfa Yao, 2017, A numerical investigation on methane combustion and emissions from a natural gas-diesel dual fuel engine using CFD model, In Applied Energy, Volume 205, Pages 153-162, ISSN 0306-2619.

12. Strålin, P., "Lagrangian CFD Modeling of Impinging Diesel Sprays for DI HCCI" Royal Institute of Technology, 2007.

13. Möller, C., "1-D Simulation of Turbocharged SI Engines - Focusing on a New Gas Exchange System and Knock Prediction" Royal Institute of Technology, 2006.

14. Courant R. K. Lewy F. H. "Uber die partiellen Differenzengleichungen der mathematischen Physik", volume 1. 1928.

15. Gamma Inc. Users Maunual, volume 61. Gamma Technologies, (2004).

16. Wilcox, D.C. "Turbulence Modeling for CFD”. 2nd edition, DCW Industries, Inc, 1998.

17. Koten H., "Comparison of Various Combustion Models within a MultiDimensional Modeling Applied to Heavy Duty CI Engine" MSc Thesis, Marmara University, 2009.

18. Gosman, A.D., Tsui, Y.Y., Flow in a Model Engine with a Shrounded Valve- A Combined Experimental and Computational Study. SAE Technical Paper Series, (1986) 850498.

19. Davis, G.C., Mikulec, A., Kent, Modeling the Effect of Swirl on Turbulence Intensity and Burn Rate in S.I. Engines and Comparison with Experiment. SAE Technical Paper Series, (1986)

20. Huh, K.Y., and Gosman, A.D. 1991. 'A phenomenological model of Diesel spray atomization', Proc. Int. Conf. on Multiphase Flows (ICMF '91), Tsukuba, 24-27 September.

21. Reitz, R.D., and Diwakar, R. 1986. 'Effect of drop breakup on fuel sprays', SAE Technical Paper Series 860469.

22. O'Rourke, P.J. 1981. "Collective Drop Effects on Vaporising Liquid Sprays". PhD Thesis, University of Princeton.

23. Schmidt, D.P., and Rutland, C.J. 2000. 'A new droplet collision algorithm', J. Comput. Phys., 164, pp. 62-80.
24. Aamir,M.A., andWatkins, A.P. 1999. 'Dense propane spray analysis with a modified collision model', ILASS-Europe'99, Toulouse, France, 5-7 July 1999.

25. Bai, C., and Gosman, A.D. 1995. 'Development of methodology for spray impingement simulation', SAE Technical Paper Series 950283.

26. Duclos, J.M., Zolver, M., Baritaud, T. "3D modelling of combustion for DI-SI engines." Oil \& Gas Science and Technology, Vol.54 (1999).

27. Colin O. and Benkenida A., The 3-Zones Extended Coherent Flame Model (ECFM3Z) for Computing Premixed/Diffusion Combustion, Oil \& Gas Sci. Tech., 59 (2004), pp. 593-609.

28. StarCD Manual 2009, "Fuel spray and atomization models" page 223-225, 2010.

29. Song, Y.S., Hong, J.W. and Lee, J.T. "The turbulence measurement during the intake and compression process for high-turbulence generation around spark timing", Proceedings of the Institution of Mechanical Engineers, Part D: Journal of Automobile Engineering, 2000, vol. 215, 493-501.

30. Zur Loye, S. O., Siebers D. L., Mckinley T. L., Ng H. K. and Primus R. J., "Cycleresolved LDV measurements in a motored Diesel engine and comparison with k- epsilon model predictions, 1989, SAE Paper 890618.

31. Kono, S., Terashita, T. T. and Kudo, H., "Study of the swirl effects on spray formation in DI engines by 3D numerical calculations", 1999, SAE Paper 910264.

32. Chen, Y.S., and Kim, S.W. 1987. 'Computation of turbulent flows using an extended k- $\varepsilon$ turbulence closure model', NASA CR-179204.

33. Launder, B.E., and Spalding, D.B. 1974. 'The numerical computation of turbulent flows', Comp. Meth. in Appl. Mech. and Eng., 3, pp. 269-289.

34. Morel, T. and Mansour, N. N., "Modeling of Turbulence in Internal Combustion Engines," SAE Technical Paper Series, 820040, International Congress and Exposition, Detroit, Mich., February 22-26, 1982.

35. Speziale, C. G. 1987. 'On nonlinear k-1 and k- $\varepsilon$ models of turbulence', J. Fluid Mech., 178, pp. 459-475. 
36. Versteeg HK; Malalasekera W (1995), An Introduction to Computational Fluid Dynamics - The Finite Volume Method, Longman Group Ltd. London, United Kingdom. 37. Yakhot, V., and Orszag, S.A. 1986. 'Renormalization group analysis of turbulenceI: Basic theory', J. Scientific Computing, 1, pp. $1-51$.

38. Yakhot, V., Orszag, S.A., Thangam, S., Gatski, T.B., and Speziale, C.G. 1992. 'Development of turbulence models for shear flows by a double expansion technique', Phys. Fluids, A4(7), pp. 1510-1520.

39. Akagawa, H., Miyamoto, T., Harada, A., Sasaki, S., Shimazaki, N., Hashizume, T., Tsujimura, K. "Approaches to Solve Problems of the Premixed Lean Diesel Combustion", SAE Paper 1999-01-0183, (1999).

40. Helmantel A, Denbratt I. HCCI Operation of a passenger car common rail DI diesel engine with early injection of conventional diesel fuel. SAE Paper 2004; 2004-01-0935.

41. Ali, H.M and Ali, A. (2014), Measurements and Semi-Empirical Correlation for Condensate Retention on Horizontal Integral-Fin Tubes: Effect of Vapour Velocity, Vol. 71, Issue 1, Page 24-33, Applied Thermal Engineering. 